\title{
Family history of breast cancer: how important is it?
}

This issue contains two manuscripts which discuss the relevance of family history to risk of breast cancer. ${ }^{12}$ In both these studies, a series of index cases with breast cancer have been interviewed and their family history of breast cancer examined. The first study involves the families of cases attending the Royal Free Hospital and University College, London, while the second was conducted using families identified by the Icelandic Cancer Registry. While many of the risks estimated here are similar to those presented in a number of previous studies, these two manuscripts should not be read as a repeat of these studies. Instead both manuscripts help put the previous epidemiological results into new perspectives.

The general conclusions that relatives of breast cancer cases are at increased risk, the extent of which is dependent upon the age of onset of the index case, higher risks being associated with early onset, have been made by a number of authors. ${ }^{3-9}$ Increased risks are also associated with bilaterality of the index case.

Formally, the risks calculated in these two studies are quite similar both to each other and those previously published. For index cases over the age of 55 the increased risk to first degree relatives is estimated to be 1.57 by Houlston et $a l^{1}$ and 1.80 by Tulinius et $a l^{2}{ }^{2}$ while for index cases below the age of 45 , Houlston et al $^{1}$ calculate the risk to be 3.85 , marginally higher than the value of 2.98 estimated by Tulinius et al. ${ }^{2}$

There are a number of important points to be made with the aid of these figures. First, the increased risk to relatives is most noticeable when the index case has early onset. However, as pointed out by Houlston et al, ${ }^{1}$ a subset of these women are at much higher risk than these previously quoted figures. Their family history is consistent with autosomal dominant inheritance of a rare allele (frequency estimate $=0.003$ ) with a lifetime penetrance for this allele of the order of 0.8 . These estimates are also consistent with previous studies. Linkage studies of this rare dominant predisposition have been conducted for many years and have recently been successful. Hall et $a l^{10}$ reported linkage of early onset breast cancer to chromosome $17 \mathrm{q}$. This report was subsequently confirmed by Narod et al, ${ }^{11}$ who also showed that families which showed autosomal dominant transmission of both breast and ovarian cancer were also linked to the same region. A related syndrome, the Li-Fraumeni syndrome, in which early onset breast cancer (often bilateral) is associated with soft tissue sarcomas and other epithelial tumours, has also been shown to result from a mutation in the p53 gene, which is located on chromosome $17 \mathrm{p} .^{12}$

There are important contributions to our thinking of a family history of breast cancer contained in these manuscripts that distinguish them from the large number of studies mentioned above. In the paper by Houlston et $a l,{ }^{1}$ the authors write from the perspective of geneticists with vast experience of clinics for families with cancer. Although their study is not based per se on those cases seen in such a clinic, the presentation is in terms of the risk for cancer in the next years or the lifetime risk of breast cancer, exactly the figures required in talking to a patient with a family history of breast cancer and discussing risks or the necessity of screening. Houlston et al $^{1}$ estimate that inherited susceptibility to breast cancer may explain almost $40 \%$ of cases diagnosed before the age of 30 to $8 \%$ by the age of 45 so that even though this susceptibility may only explain 4 to $5 \%$ of all breast cancer, it is a common cause of early onset breast cancer. This prediction can now be tested using the DNA marker close to the $17 \mathrm{q}$ locus identified by Hall et al. ${ }^{10} \mathrm{~A}$ similar calculation for the Cancer and Steroid Hormone study conducted in the USA gives very similar estimates for the importance of inherited susceptibility. ${ }^{13}$

The manuscript by Tulinius et $a l,{ }^{2}$ by contrast, is basic epidemiological research but with the important advantage of being able to examine the family history of breast cancer in terms of extended pedigrees and risks to second and third degree relatives. Their observation of increased risk for these more distant relatives is consistent with the importance of genetic susceptibility to risk. Indeed, following Risch, ${ }^{14}$ if breast cancer resulted from susceptibility at a single locus, and if the risk to first degree relatives were indeed 2.26 , then this would translate into a risk to second degree relatives of 1.63 , which is similar to the estimate of 1.43 given in the manuscript.

These are exciting times for those interested in genetics and cancer susceptibility, especially to breast cancer. These two manuscripts help us to recognise the importance of family history and to realise that, in some cases, family history is exceptionally strong. Even though common cancers will frequently occur in families simply because of their commonness, the clues of early onset or bilateral cases should alert us that genetic predisposition could be playing a role.

D TIMOTHY BISHOP

Genetic Epidemiology Laboratory, Imperial Cancer Research Fund, $3 K$ Springfield House, Hyde Terrace, Leeds LS9 9LU. 
1 Houlston RS, McCarter E, Parbhoo S, Scurr JH, Slack J. Family history and risk of breast cancer. $\mathcal{f}$ Med Genet Family history

2 Tulinius H, Sigvaldason H, Olafsdóttir G, Tryggvadóttir L. Epidemiology of breast cancer in families in Iceland. $\mathcal{F}$ Med Genet 1992;29:158-64.

3 Adami HO, Hansen J, Jung B, Rimsten A. Familiality in breast cancer: a case-control study in a Swedish population. Br $\mathcal{f}$ Cancer 1980;42:71-7.

4 Bain C, Speizer FE, Rosner B, Belanger C, Hennekens $\mathrm{CH}$ Family history of breast cancer as a risk factor for the disease. Am F Epidmiol 1980;111:301-8.

5 Tulinius $\mathrm{H}$, Day NE, Bjarnason O, et al. Familial breast cancer in Iceland. Int $\mathcal{f}$ Cancer 1982;29:365-71.

6 Satin RW, Rubin GL, Webster LA, et al. Family history and the risk of breast cancer. $\mathcal{F A M A} 1985 ; 253: 1908-13$.

7 Schwartz AG, King MC, Belle SH, Satariano WA, Swanson GM. Risk of breast cancer to relatives of young Swanson GM. Risk of breast cancer to relatives of young
breast cancer patients. $\mathcal{f}$ Natl Cancer Inst 1985;75:665-8.
8 Claus EB, Risch N, Thompson WD. Age of onset as an indicator of familial risk of breast cancer. Am $\mathcal{F}$ Epidemiol indicator of familial risk of breast cancer. Am $\mathcal{F}$ Epidemiol
1990;131:961-72.

9 Byrne C, Brinton LA, Haile RW, Schairer C. Heterogeneity of the effect of family history on breast cancer risk. Epidmiology 1991;2:276-84.

10 Hall JM, Lee MK, Newman B, et al. Linkage of early-onset familial breast cancer to chromosome $17 \mathrm{q} 21$. Science 1990;250:1684-9.

11 Narod SA, Feunteun J, Lynch HT, et al. A familial breastovarian cancer locus on chromosome 17q12-q23. Lancet $1991 ; \mathbf{i i}: 82-3$.

12 Malkin D, Li FP, Strong LC, et al. Germ line p53 mutations in a familial syndrome of breast cancer, sarcomas and other neoplasms. Science 1990;250:1233-8.

13 Bishop DT. The importance of inherited predisposition to cancer. Cancer Topics 1991;8:66-8.

14 Risch N. Linkage strategies for genetically complex traits. I. Multilocus models. Am f Hum Genet 1990;46:222-8. 